\title{
Assessment of Knowledge, Attitude and Practice of Tb Transmission and Prevention among the Communities in Holeta Town
}

\author{
Tilahun Bogale Moreda ${ }^{2 *}$ and Digafe Tsegaye Nigatu ${ }^{1}$ \\ ${ }^{1}$ Lecturer at department of Public Health, College of Medicine \&Health Sciences, \\ Ambo University, Ambo, Ethiopia \\ ${ }^{2}$ Associate Professor at department of Public Health, College of Medicine \& Health \\ Sciences, Ambo University, Ambo, Ethiopia.
}

\section{Research Article}

Volume 2 Issue 1

Received Date: March 21, 2018

Published Date: May 02, 2018

*Corresponding author: Tilahun Bogale Moreda (PhD), Associate Professor at department of Public Health, College of Medicine \& Health Sciences, Ambo University, Ambo, Ethiopia, Email: mikiasbo12@gmail.com

\section{Abstract}

Background: Though tuberculosis (TB) is a preventable and curable, still it is a problem in worldwide, including Ethiopia. Limited knowledge about the disease could have an effect on the patients who seek health care services and continue the TB transmission within the public. Hence, the study was conducted in Holeta town to assess knowledge, attitude and practice (KAP) towards the cause, transmission and prevention of tuberculosis (TB).

Methods: Community based cross-sectional survey; involving 385 randomly selected individuals were employed in Holeta town from February to May, 2017. SPSS software version 20.0 was used to enter, clean and analyze the collected data.

Results: Three hundred thirty nine (90.2\%) of the study participants reported that they ever heard about tuberculosis. Thirty four percent of the study subjects thought that the cause of tuberculosis is bacteria. Respondents' awareness about TB transmission from TB patient to new susceptible individuals were $75 \%$ and thirty nine percent be familiar with transmission of TB can be preventable. Persistent cough (34.2\%) was the often affirmed sign and symptom of the disease.

Conclusion: Basic TB awareness among the communities in Holeta town is universal, which is not converted into the knowledge about the cause of the tuberculosis. Therefore, emphasis needs to be intended for bringing a considerable change in the knowledge about TB.

Keywords: KAP; Tuberculosis; Community; Holeta town 


\section{Introduction}

Tuberculosis (TB) remains a major global public health problem [1]. The disease is caused by Mycobacterium tuberculosis complex, which is an infectious disease. The disease mainly affects the lung, but can also attack other parts of the body. The route of transmission is through air from infected individual to others during coughing, sneezing, singing or talking. Many TB infections do not show apparent sign and symptoms, which termed as latent TB [2,3]. Tuberculosis is also more common among men than women, and affects mostly adults in the economically productive age groups. The probability of developing TB among individuals with HIV is much greater [4].

Globally 9.4 million new cases and fourteen million old cases happened in a year 2010. In Africa, particularly sub-Saharan Africa faces the challenge of tuberculosis outbreak [5]. Among the world's 22 high burden countries, Ethiopia ranks $7^{\text {th }}$, which have 300 and 470 new cases and old cases per 100,000 populations, respectively [6].Tuberculosis is the common cause of mortality and morbidity in Ethiopia [7].

Ethiopia as multi-cultural country, the knowledge of TB has been mentioned to demonstrate considerable spatial changes [8]. Moreover, through the electronic media and health education campaigns, information about healthcare can attain many public rapidly and boost the knowledge level among individuals [9].

Different studies demonstrated that limited knowledge was found to be observed among the uneducated, women, countryside residences, poor, and youngsters'. Additionally, lower than half of the study subjects were conscious about the TB treatment and diagnosis, which could act as factor to diagnosing tuberculosis and considerably have an effect on the case notification rate [10-13].

Factors contributed to the disease acquiring, epidemiological burden, and disease development includes low income, HIV, inadequate nutrition, cigarette smoking, low access health services infrastructure, lack of consciousness and information about the cause, transmission mode, and signsymptoms of the disease, demographic features, poor health education, and tradition or culture related beliefs. The above mentioned factors considered to have crucial impact on the patients' health seeking behaviors which delay in diagnosis, treatment $[4,14,15]$.

In addition, the social relationships and ethical identity of people afflicted by TB disease affected if they have negative concept of the disease and also it has impact on TB control efforts in general [16]. Because of these, enhancing communities' awareness about tuberculosis and involving the people in the disease control considered to be WHO basic component of the "stop TB strategy" [17].

Of over 94 million population of Ethiopia, rural area residents are accounted $85 \%$ that are far away from health facilities, media, consequently knowledge, attitude, and practice assessment among people toward the disease were incredibly essential to collect data for identification of the the problem, program planning and intervention. Therefore, the aim is to assess individuals' knowledge, attitude, and practice toward disease (TB).

\section{Method and Materials}

\section{Study Area}

The study was carried out in Holeta town which is situated at $40 \mathrm{~km}$ west of capital Addis Ababa Ethiopia.It was established in 1902 during Minilik II regime. According to central Statistics of Ethiopia (CSE) 2007 total human population of Holeta town was 25,593.Based on the information obtained from municipality, the town is categorized into eight administrative kebeles.

The source population was all individuals whose age 20 years and above residing in the randomly selected four kebeles. Mentally ill and guest individuals were excluded from this study.

To determine the sample size, a single population proportion formula was used. Assuming that $50 \%$ of the respondents had knowledge of $\mathrm{TB}$ and with further assumption of $95 \%$ confidence level, 5\% margin of error, and $10 \%$ non respondent rate, a total sample of 385 study subjects were required .During sampling, four kebeles were selected using random sampling technique and the calculated sample was proportionally distributed to the selected kebeles according to the number of households. From each selected kebele, households were chosen using systematic random sampling technique. Finally, from all the eligible study participants in the households, only a single individual was selected randomly. In the absence of suitable study participant in the given household, a replacement was made by an individual in the next household.

A standardized questionnaire was utilized, which consists of questions on socio demographic characteristics and knowledge, attitude and practice towards tuberculosis of study participants. The data collection tool was first prepared in English. It was translated to Oromiffa, which is a local language and back to English again in order to maintain the instrument validity. Nine data collectors and one 


\section{Epidemiology international journal}

supervisor who were public health students from Ambo University, department of Public health were recruited. For data collectors and supervisors, a one day intensive training was given before the pretest had been undertaken. The supervisor and principal investigator had closely followed the day-to-day data collection process and ensure completeness and consistency daily. Structured and pretested questionnaires were utilized to collect the data from the respondents by face to face interview.

The statistical analysis was done using SPSS software version 20.0. After the data entry, it was edited and cleaned before analysis. Frequency, percentage and descriptive summaries were utilized to explain the study variables.

Ethical clearance was obtained from Ambo University, College of Medicine and Health Sciences
Institutional Review Board. Supportive letter was taken to Holeta town Municipality office. Informed verbal consent was obtained from each respondent.

\section{Results}

\section{Socio-Demographic Characteristics}

Three hundred seventy six respondents with a response rate of $(97.6 \%)$ were participated. The respondents' mean age was $22.7(+1.67$ SD years). Female respondents constituted (56.9\%), 44.7\% were between the age group of 35 to 44 years and their age ranged between 18-65 years, $72.1 \%$ were Oromo ethnic, $46.5 \%$ were Orthodox Christian followers, $76.1 \%$ were married couples, $42.3 \%$ were attended primary school, $36.7 \%$ were private worker by occupation (Table 1).

\begin{tabular}{|c|c|c|}
\hline Variables & Frequency (n) & Percent (\%) \\
\hline \multicolumn{3}{|l|}{ Sex } \\
\hline Male & 162 & 43.1 \\
\hline Female & 214 & 56.9 \\
\hline \multicolumn{3}{|l|}{ Age } \\
\hline $15-24$ & 59 & 15.7 \\
\hline $25-34$ & 118 & 31.4 \\
\hline $35-44$ & 168 & 44.7 \\
\hline$>45-54$ & 31 & 8.2 \\
\hline \multicolumn{3}{|l|}{ Ethnicity } \\
\hline Oromo & 271 & 72.1 \\
\hline Amhara & 57 & 15.15 \\
\hline Gurage & 40 & 10.6 \\
\hline Tigre & 6 & 1.6 \\
\hline \multicolumn{3}{|l|}{ Religion } \\
\hline Orthodox & 175 & 46.5 \\
\hline Protestant & 145 & 38.5 \\
\hline Muslim & 28 & 7.4 \\
\hline Others & 20 & 5.6 \\
\hline \multicolumn{3}{|l|}{ Marital status } \\
\hline Unmarried & 90 & 23.9 \\
\hline Married & 286 & 76.1 \\
\hline \multicolumn{3}{|l|}{ Level of education } \\
\hline Illiterate & 130 & 34.6 \\
\hline Primary school & 159 & 42.3 \\
\hline Secondary school & 39 & 10.4 \\
\hline College/university & 48 & 12.8 \\
\hline \multicolumn{3}{|c|}{ Current occupational status } \\
\hline Gov't employed & 103 & 27.4 \\
\hline Private & 138 & 36.7 \\
\hline Daily worker & 37 & 9.8 \\
\hline Housewife & 98 & 26.1 \\
\hline
\end{tabular}

Table 1: Socio-demographic characteristics of respondents in Holeta town, Oromia Regional State, Ethiopia, May 2017. 


\section{Epidemiology international journal}

\section{Knowledge Related Characteristic of Respondents}

An overwhelming majority $(90.2 \%)$ had heard of Tuberculosis disease without a substantial sexual category. In the study area, the major sources of information about tuberculosis include media, and health workers (Table 2).

Thirty five percent of the respondents were responded that cold air is a cause for tuberculosis, while others response was $34.0 \%$ "M. Tuberculosis or Bacteria", $21.8 \%$ poor hygiene and $8.8 \%$ smoking. Regarding to respondents' knowledge about TB transmission, coughing droplet (75.4\%) was the mainly reported mode of transmission for the disease. Sharing dish $(14.2 \%)$ and shaking hands $(10.4 \%)$ were the other mentioned possible modes of transmission. Concerning sign and symptom knowledge about $\mathrm{TB}$, continual cough for two weeks or above (34.2\%) was the frequently responded answer, followed by weight loss (33.6\%).Respondents were also mentioned other sign and symptom such as persistent fever $(17.5 \%)$ and an ongoing fatigue (14.7\%).
Majority (93.4\%) of the respondents responded that tuberculosis transmission would be avoidable. When asked about the protective measures for $\mathrm{TB}$, response included cover mouth when sneezing or coughing (38.5\%), avoiding hand shaking (13.7\%), washing hands $(12.3 \%)$, isolating TB patients (10.4\%), avoiding sharing dishes, vaccination (8.8\%) and having sufficient ventilation (7.2\%) (Table 3).

\begin{tabular}{|c|c|c|}
\hline Variables & Frequency (n) & Percent (\%) \\
\hline Heard of TB & & \\
\hline Yes & 339 & 90.2 \\
\hline No & 37 & 9.8 \\
\hline Sources of information & & \\
\hline Media (radio, TV) & 304 & 33.9 \\
\hline Health institutions & 118 & 13.2 \\
\hline Health professionals & 293 & 32.7 \\
\hline Teachers & 114 & 12.7 \\
\hline Friends & 67 & 7.5 \\
\hline
\end{tabular}

Table 2: Communities' source of information about Tuberculosis in Holeta town, Oromia Regional State, Ethiopia, May 2017.

\begin{tabular}{|c|c|c|}
\hline Variables & Frequency (n) & Percent (\%) \\
\hline Cause of TB & & 35.4 \\
\hline Cold wind & 133 & 34.0 \\
\hline Bacteria & 128 & 8.8 \\
\hline Smoking & 33 & 21.8 \\
\hline Poor hygiene & 82 & 75.4 \\
\hline Mode of transmission & 312 & 14.2 \\
\hline Through coughing droplet & 59 & 10.4 \\
\hline Though sharing dish & 43 & 34.2 \\
\hline Through shaking hands & & 33.6 \\
\hline Signs and symptom & 223 & 14.7 \\
\hline Cough for 2 weeks or above & 219 & 17.5 \\
\hline Weight loss & 96 & 93.4 \\
\hline Ongoing fatigue & 114 & 6.6 \\
\hline Persistent fever & & \\
\hline Possible to prevented TB & 351 & 38.5 \\
\hline Yes & 25 & 12.3 \\
\hline No & & 13.7 \\
\hline Prevention methods & 359 & 10.4 \\
\hline Washing hands & 115 & 9.1 \\
\hline Avoiding handshakes & 128 & 8.8 \\
\hline Isolating TB patients & 97 & 7.2 \\
\hline Avoid sharing dishes & 85 & \\
\hline Vaccination & 82 & \\
\hline Sufficient ventilation & 67 & \\
\hline Cover mouth when oughing/sneezing & & \\
\hline
\end{tabular}

Table 3: Knowledge of respondents about TB in Holeta town, Oromia Regional State, Ethiopia, May 2017.

\section{Attitudinal Related Characteristics}

Majority $(79.1 \%)$ of the respondents disagree that TB is ordered by God as a punishment, while sixteen percent agreed. Fifty four percent of the respondents agree that regular sputum examination is useful, while others disagreed (13.3\%), and neutral (33.0\%). Fifty 
four percent of respondents think that TB has relationship with other diseases. In contrary, 13.3\% considered, it has no relationship with other diseases and 33\% did not know whether TB has relation with other diseases or not. High proportion (75.5\%) of the respondents, considered that overcrowding has contribution to TB transmission. Concerning to the respondents' feeling towards TB disease, (24.7\%) agree that tuberculosis can be prevented by holly water and traditional medicine, $53.7 \%$ disagree, and $21.5 \%$ neither agreed nor disagreed (Table 4).

\begin{tabular}{|c|c|c|}
\hline Variables & Frequency (n) & Percent (\%) \\
\hline \multicolumn{3}{|c|}{ TB ordered by God as punishment } \\
\hline Agree & 59 & 15.6 \\
\hline Neutral & 20 & 5.3 \\
\hline Disagree & 297 & 79.1 \\
\hline \multicolumn{3}{|c|}{ Regular sputum examination is useful } \\
\hline Agree & 202 & 53.7 \\
\hline Neutral & 124 & 33.0 \\
\hline Disagree & 50 & 13.3 \\
\hline \multicolumn{3}{|c|}{ TB has any relation with other disease? } \\
\hline Has relationship & 202 & 53.7 \\
\hline Has no relationship & 50 & 13.3 \\
\hline I don't know & 124 & 33.0 \\
\hline \multicolumn{3}{|c|}{ Overcrowding has contribution to TB transmission } \\
\hline Agree & 284 & 75.5 \\
\hline Neutral & 244 & 64.8 \\
\hline Disagree & 67 & 17.8 \\
\hline \multicolumn{3}{|c|}{ TB can be prevented by holly water and traditional medicine } \\
\hline Agree & 93 & 24.7 \\
\hline Neutral & 81 & 21.5 \\
\hline Disagree & 202 & 53.7 \\
\hline
\end{tabular}

Table 4: Communities' attitude about TB in Holeta town, Oromia regional state, Ethiopia May, 2017.

\section{Practice Related Characteristic of Respondents}

One hundred seventy eight (47.3\%) responded that they cover their mouth during coughing to prevent TB transmission. Majority $(86.2 \%)$ responded that they were opened window when they were in house. only three $(0.8 \%)$ of the respondents were used traditional methods to be prevented from TB, but $99.02 \%$ didn't know about the methods. Furthermore, $32.7 \%$ of the respondents dispose sputum in prepared objects, $39.6 \%$ disposes inside the hole and $27.6 \%$ dispose anywhere. The majority (43.6\%) of respondents were indicated that they attend health facilities as soon as coughing started.

\section{Discussion}

This finding indicated that tuberculosis is recognizable to the entire public in the present study area, as the largest part (90.2\%) of the respondents had showed that they have heard of Tuberculosis, which is comparable to earlier studies $(92.8 \%)$ conducted in Somalia region, Ethiopia [18] and in Afar region (95.6\%), Ethiopia [19], of the respondents were conscious of the disease. Though, in line with earlier studies southwest Ethiopia [20] as well as in Afar region, [19], the respondents had inadequate information about $M$. bacterium tuberculosis as a disease causing agent of TB. Instead, majority of the respondents supposed mostly either cold air or smoking as a cause of TB, which is in conformity with other findings.

According to this finding, the respondents had fundamental knowledge about the general sign and/or symptom of tuberculosis and its mode of transmission, which conform with previously conducted studies $[19,20]$. Incidentally, it was mentioned that cough persisted for two or more weeks, weight loss were the frequent sign/symptom of Tuberculosis. When an individual cough/sneezes, share dishes, shakes hands with the patients were the common supposed mode of transmission in different studies [20].

Another very crucial feature well-known in this particular study was that significant portion of the respondents was aware of the prevention of tuberculosis, which is comparable to a study conducted 
in southwest Ethiopia. Accordingly, covering mouths and nose when a patient sneezes, isolating the patient, avoiding sharing dishes with the patients, and good nourishment as a good prevention measures were like wise mentioned by previous studies from Ethiopia $[19,20]$.

\section{Limitations}

This study was utilized only a quantitative method, but lacks qualitative which is crucial to discover indeepness view about the contributing factors for tuberculosis is affecting its strength. Absence of information on HIV, lack of questions about MDR, lack of current and former family TB infection and the crosssectional nature of the study, which is unable to correctly demonstrate the way of relationship or association.

\section{Conclusion}

The findings indicated that the people in Holeta town had fundamental consciousness about tuberculosis. However, information about the disease causing agent among community members was not sufficient. Therefore, health information aimed at bringing a considerable change in their consciousness particularly about the primary agent that cause tuberculosis, transmission mode and prevention mechanism is important.

\section{Conflict of Interests}

The authors declared that there are no competing interests.

\section{Acknowledgement}

Ambo University, College of Medicine and Health Sciences should be acknowledged for supporting financially to carry out this research. We are also acknowledging the respondents who participated in this study.

\section{References}

1. World Health Organization (2012) WHO report, Geneva; World Health Organization: Global Tuberculosis Control. WHO report, Geneva 2010.

2. Cole E, Cook C (1998) Characterization of infectious aerosols in health care facilities: an aid to effective engineering controls and preventive strategies. Am J Infect Control 26(4): 453-464.

3. Nicas M, Nazaroff WW, Hubbard A (2005) Toward understanding the risk of secondary airborne infection: emission of reparable pathogens. J Occup Environ Hyg 2(3): 143-154.

4. WHO (2012) Global Tuberculosis Report.

5. Mathema B, Kurepina NE, Bifani PJ, Kreiswirth BN (2006) Molecular epidemiology of tuberculosis: current insights. Clin Microbiol Rev 19(4): 658-685.

6. WHO (2010) Tuberculosis Profile.

7. Ministry of Health (2008) TB; Leprosy and TB/HIV prevention and control program manual. Addis Ababa: Ministry of Health.

8. Amo-Adjei J, Kumi-Kyereme A (2013) Myths and misconceptions about tuberculosis transmission in Ghana. BMC Int Health Hum Rights 13(1): 1.

9. Baker L, Wagner TH, Singer S, Bundorf MK (2003) Use of the Internet and e-mail for health care information: results from a national survey. JAMA 289(18): 2400-2406.

10. Hoa NP, Chuc NT, Thorson A (2009) KAP about tuberculosis and choice of communication channels. Health Policy 90(1): 8-12.

11. Mushtaq MU, Majrooh MA, Ahmad W, Rizwan M, Luqman MQ, et al. (2010) KAP regarding tuberculosis. Int J Tuberc Lung Dis 14: 303-310.

12. Mushtaq MU, Shahid U, Abdullah HM, Saeed A, Omer F, et al. (2011) Urban-rural inequities in KAP regarding tuberculosis. Int J Equity Health 10: 8.

13. Storla DG, Yimer S, Bjune GA (2008) A systematic review of delay in the diagnosis and treatment of tuberculosis. BMC Public Health 8: 15.

14. Lawn SD, Afful B, Acheampong JW (1998) Pulmonary tuberculosis: diagnostic delay. Int J Tuberc Lung Dis 2(8): 635-640.

15. Hassmiler KM (2006) The association between smoking and tuberculosis. Salud Publica Mex 48: S201-S216.

16. Shimao T (1989) Drug resistance in tuberculosis control. Tubrcle 68: 5-15.

17. World Health Organization (2006) The global plan to stop TB, 2006-2015: in actions for life-towards a world free of tuberculosis. Geneva: World Health Organization.

18. Melaku S, Hardeep RS, Getahun AA (2013) Pastoralist community's perception of Tuberculosis. A quantitative study from shinile area of Ethiopia. Hindawi publishing corporation Tuberc res treat. 


\section{Epidemiology international journal}

19. Legesse M, Ameni G, Mamo G, Medhin G, Shawel D, et al. (2010) Knowledge and perception of pulmonary tuberculosis in pastoral communities in the middle and lower Awash valley Afar region, Ethiopia. BMC Public Health 10: 187.
20. Abebe G, Amare Deribew, Ludwig Apers, Kifle Woldemichael, Jaffer Shiffa, et al. (2010) Knowledge, health seeking behavior and perceived stigma towards tuberculosis among tuberculosis suspects in a rural community in southwest Ethiopia. Plos One. 